\title{
Polunnomial Analysis of Dental Arch form of Nepolese Adult Subjects
}

\author{
Dr Rabindra Man Shrestha \\ Associate Professor, Department of Orthodontics \\ Kantipur Dental College, Kathmandu, Nepal
}

Correspondence: rabindraortho@gmail.com

\section{ABSTRACT}

Introduction: Human dental arch acquires stable form and dimensions with the attainment of adulthood. The orthodontic treatment regimen signifies the predetermination of the shape and type of dental arch form of a particular adult population to harmonize with their natural pattern. The use of predetermined arch form helps in diagnosis, treatment planning and stability of orthodontic treatment results.

Objective: To analyze the dental arch forms of Nepalese adults and to classify them into morphological types.

Materials \& Method: Predetermined transverse and sagittal dimensions on dental stone models of one hundred Nepalese adults aged 17-32 years with normal occlusion and dentofacial proportion were measured using standardized Boley gauze. The analysis was done according to Raberin's mathematical sixth degree polynomial method. The study compared the gender difference among the Nepalese samples.

Result: The distribution of the Nepalese arch form types were; $26 \%$ flat arch, $24 \%$ wide arch, $19 \%$ pointed arch, $18 \%$ narrow arch and $13 \%$ mid arch.

Conclusion: Considerable variation in distribution of dental arch form types found between Nepalese male and female samples and among population groups. The analysis enables the mathematical method that predetermines the dental arch form of the individual orthodontic patient.

Key words: arch form, orthodontic, polynomial, sagittal, transverse

\section{INTRODUCTION}

Human dental arch forms have been described using simple qualitative descriptions as well as complex mathematical methods. One of the earliest descriptions of the dental arch was given by Hunter in 1839 as the normal anatomic arrangement of teeth. In 1870 Muhlreiter ${ }^{2}$ presented a detailed description of the dentition. Broombell ${ }^{3}$ in 1902 stated that the teeth are arranged in the jaws in the form of parabolic curves. Angle $^{4}$ in 1907 recognized dental arch as parabolic but he stated that arch form varied greatly with race and type of the individual.

The term 'arch' has long been known architecturally as a stable curved arrangement. Lasher ${ }^{5}$ in 1934 noted similarity between the dental arch form and natural arch formations. He compared dental arch with architectural design; the voussoir arch.

Hawley ${ }^{6}$ proposed a geometric method for determining the dental arch for orthodontic purpose using the ideas of Bonwill. ${ }^{7}$ Sicher ${ }^{8}$ described the form of the upper arch as elliptic, while that of the lower arch as parabolic. MacConaill et $a^{9}$ described dental arch to the conformity of catenary curve. Scott, 10 Burdi ${ }^{11}$ showed embryonic processes of the developing jaws as the characteristic catenary forms. Biggerstaff, 12 Sampson ${ }^{13}$ fitted conic sections like parabola, hyperbola, ellipse to dental arches to examine the variability of dental arch shapes. In 1972, the Brader arch form ${ }^{14}$ was developed, which is based on the mathematical formula of trifocal ellipse. It defined how the teeth arrange themselves in response to muscular pressure. 
Many researchers studied dental arch form using polynomial curves. Lu ${ }^{15}$ formulated fourth degree orthogonal polynomial curve to represent dental arch. Ferrario et $a^{16}$ analyzed arch shapes by fourthorder polynomial and mixed elliptical and parabolic interpolation. Ferrario et $a^{17}$ used Euclidean distance matrix for arch form analysis. Kasai et $a^{18}$ and Valenzuela et a ${ }^{19}$ described dental arch forms using Fourier transformations. Begole et $a^{20}$ demonstrated the method using cubic spline function to model the dental arch form. Rocky Mountain Data Systems ${ }^{21}$ used computer-derived methods, while Interlandi22 developed Incisor Curvature Radius Gauges to individualize the dental arch forms. Mclaughlin et $a{ }^{23}$ in 1999 devised 'clinical arch form' based on the points where the arch wire would lie in the bracket slots.

Raberin et al $^{24}$ in 1993 determined dental arch forms of untreated French adults with normal occlusion. They considered measurements of the mandibular arch and the ratios of the dimensions to develop a classification system of the dental arch.

Anthropologists assume that various racial types have differently shaped arches. Aitchison ${ }^{25}$ showed dental arch variations among racial groups. The present study aims to determine dental arch form of the Nepalese adults and establish norms that could be applied to the orthodontic diagnosis and treatment planning of the Nepalese orthodontic patients.

\section{MATERIALS AND METHOD}

Dental arch forms of the Nepalese adult samples were analyzed according to the method described by Raberin, Laumon, Martin et al. ${ }^{24}$ The transverse and sagittal measurements of the dental arches were determined on mandibular casts. The reference points were determined as; mid-incisal edge on the labial side, canine cusp tips, mesio-buccal cusps of first molars and disto-buccal cusp tips of second molars.

The samples included one hundred mandibular dental casts of the Nepalese adults aged 17-32 years (mean 20 years) with equal male to female ratio. The samples were selected according to the inclusion criteria of normal occlusion with full complement of permanent teeth (with or without third molars), Class I canine and molar relation, symmetrical dental arch, and proportional maxilla-mandibular relationship. The standardized Boley gauge of 0.01 millimeter accuracy (Dentaurum, Munchner model No. 042-721-00) was used to measure the dimensions.

The transverse measurements of the mandibular dental arches were inter-canine width $\left(L_{33}\right)$ measured between the canine tips, mean inter-molar width $\left(\mathrm{L}_{66}\right)$ between the mesio-buccal cusps of the first molars, and posterior inter-molar width $\left(L_{77}\right)$ between the disto-buccal cusps of the second molars. The sagittal measurements were canine depth $\left(L_{31}\right)$ measured from the mid-incisal edge to the line joining the cusp tips of the canines, mean arch length $\left(\mathrm{L}_{61}\right)$ measured from the mid-incisal edge to the line joining the mesiobuccal cusps of the first molars, and the total length $\left(L_{71}\right)$ measured from the incisal edge to the line joining the disto-buccal cusps of the second molars (Figure 1).

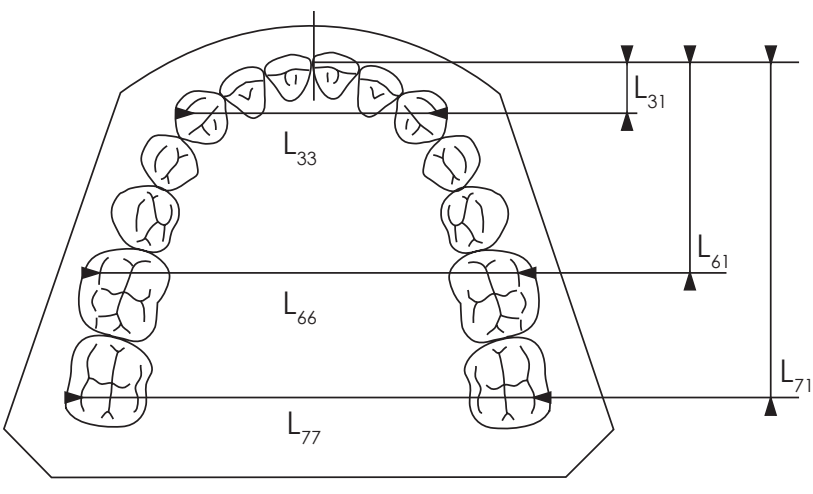

Figure 1: Transverse and sagittal measurements in mandibular cast

Six transverse and sagittal dimensions characterize both the form and dimension of the dental arch (Figure 2). The five independent ratios that determined the arch forms were; $\mathrm{L}_{31} / \mathrm{L}_{33^{\prime}} \mathrm{L}_{61} / \mathrm{L}_{66^{\prime}} \mathrm{L}_{71} / \mathrm{L}_{77^{\prime}} \mathrm{L}_{33} / \mathrm{L}_{66^{\prime}}$ and $\mathrm{L}_{61} / \mathrm{L}_{71}$. Based on the five independent ratios, the arch forms were classified as;

- Form 1 Narrow: 3 sagittal/transverse ratios are positive

- Form 2 Wide: 3 sagittal/transverse ratios are negative

- $\quad$ Form 3 Mid: None of the ratios significantly deviates from the average

- Form 4 Pointed: Only $L_{31} / L_{33}$ ratio has the intensity higher than the average

- Form 5 Flat: Only $\mathrm{L}_{31} / \mathrm{L}_{33}$ ratio has the intensity below the average 


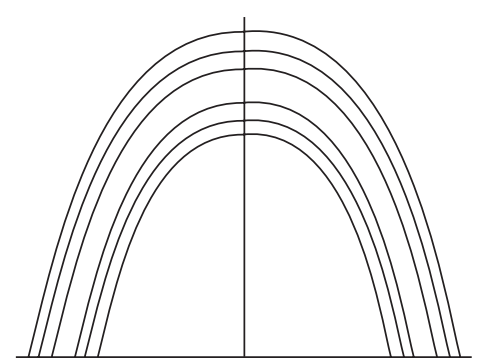

Narrow

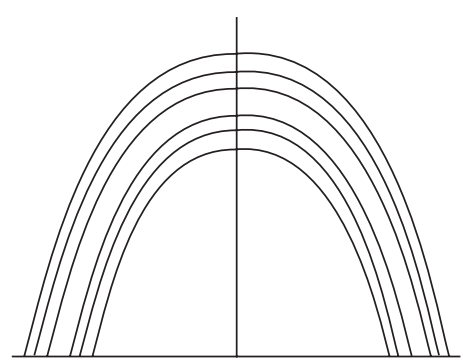

Wide

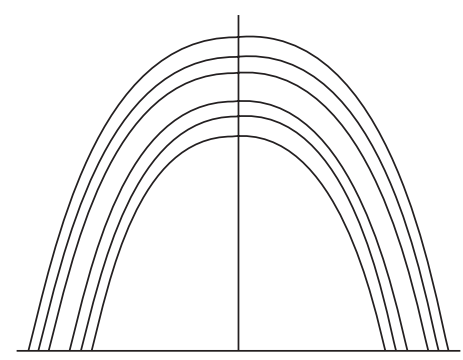

Mid

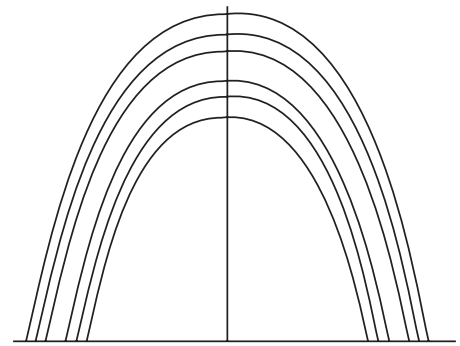

Pointed

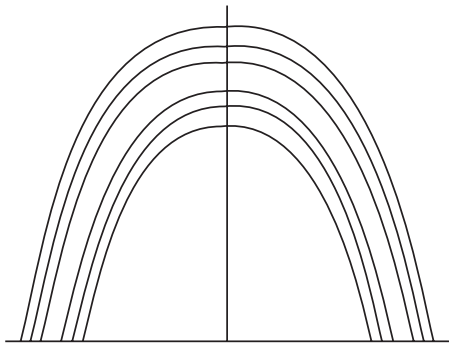

Flat

Figure 2: Dental arch form types according to Raberin's classification

The independent ratios were computed for all samples and relative deviation between the mean value of a given ratio for a given form and mean value of the same ratio for the whole sample were computed to distinguish the five dental arch forms of the Nepalese samples in graphical representation. Each of the five forms distinguishes itself from the average form which is determined on the basis of the whole sample.

Relative deviation $=\frac{\text { Mean value of given sample }- \text { Mean value of the whole sample }}{\text { Mean value of the whole sample }}$

The statistical analyses were performed using computerized software of SPSS. Student's t-test was used to compare the difference between the arch dimensions of male and female subjects.

\section{RESULT}

Transverse and sagittal dimensions of the mandibular dental arch of combined male and female subjects are shown in Table 1. All transverse dimensions of males were significantly greater than those of the female subjects. However the mean sagittal dimensions $\mathrm{L}_{31}$ and $\mathrm{L}_{61}$ were greater in females (Table 2).

Table 1: Mean mandibular arch dimensions of combined Nepalese female and male subjects

\begin{tabular}{|c|c|c|c|c|}
\hline \multicolumn{2}{|c|}{ Dimension (in mm) } & Mean & SD & Range \\
\hline \multirow{3}{*}{ Transverse } & $\mathrm{L}_{33}$ & 25.48 & 1.52 & 8.10 \\
\cline { 2 - 5 } & $\mathrm{L}_{66}$ & 45.66 & 2.54 & 14.40 \\
\cline { 2 - 5 } & $\mathrm{L}_{77}$ & 53.66 & 3.11 & 21.10 \\
\hline \multirow{3}{*}{ Sagittal } & $\mathrm{L}_{31}$ & 5.28 & 0.82 & 4.10 \\
\cline { 2 - 5 } & $\mathrm{L}_{61}$ & 22.99 & 1.64 & 7.70 \\
\cline { 2 - 5 } & $\mathrm{L}_{71}$ & 37.73 & 2.17 & 9.90 \\
\hline
\end{tabular}


Table 2: $t$-Test of significance for the difference between the sexes for mean mandibular dimensions

\begin{tabular}{|c|c|c|c|c|c|c|c|}
\hline \multirow{2}{*}{\multicolumn{2}{|c|}{ Dimension }} & \multicolumn{2}{|c|}{ Female } & \multicolumn{2}{|c|}{ Male } & \multirow{2}{*}{$p$-value } & \multirow{2}{*}{ Significance } \\
\hline & & Mean & SD & Mean & SD & & \\
\hline \multirow{3}{*}{ Transverse } & $\mathrm{L}_{33}$ & 25.11 & 1.22 & 25.86 & 1.70 & 0.013 & $*$ \\
\hline & $\mathrm{L}_{66}$ & 44.44 & 2.00 & 46.88 & 2.45 & 0.000 & $* * *$ \\
\hline & $\mathrm{L}_{77}$ & 52.03 & 2.22 & 55.28 & 3.04 & 0.000 & $* * *$ \\
\hline \multirow{3}{*}{ Sagittal } & $\mathrm{L}_{31}$ & 5.32 & 0.85 & 5.24 & 0.79 & 0.602 & NS \\
\hline & $\mathrm{L}_{61}$ & 23.09 & 1.45 & 22.88 & 1.81 & 0.528 & NS \\
\hline & $L_{71}$ & 37.50 & 1.94 & 37.96 & 2.38 & 0.291 & NS \\
\hline
\end{tabular}

$\left({ }^{*} P<0.05, * * * P<0.001, N S=\right.$ not significant $)$

The classification of arch form was based on five independent ratios of the predetermined arch dimensions. Relative deviation between the mean values of a given ratio for a given form and the mean value of the same ratio for the whole sample was computed (Table 3) which is presented in graphical form in Figure 3.

Table 3: Mean value of the independent ratios

\begin{tabular}{|c|c|c|c|c|}
\hline & Mean & Standard deviation & Mean of the Relative Deviation & SD of the Relative Deviation \\
\hline $\mathrm{L}_{31} / \mathrm{L}_{33}$ & 0.20773 & 0.0339 & -0.002007 & 16.3178 \\
\hline $\mathrm{L}_{61} / \mathrm{L}_{66}$ & 0.50500 & 0.0461 & -0.0009712 & 9.1339 \\
\hline $\mathrm{L}_{71} / \mathrm{L}_{77}$ & 0.70540 & 0.0553 & -0.0001145 & 7.8447 \\
\hline $\mathrm{L}_{33} / \mathrm{L}_{66}$ & 0.59913 & 0.0702 & -0.000543 & 11.7098 \\
\hline $\mathrm{L}_{61} / \mathrm{L}_{71}$ & 0.60906 & 0.0218 & -0.0001136 & 3.5779 \\
\hline
\end{tabular}

Figure 3: Relative deviation for each form of each ratio from its overall mean value

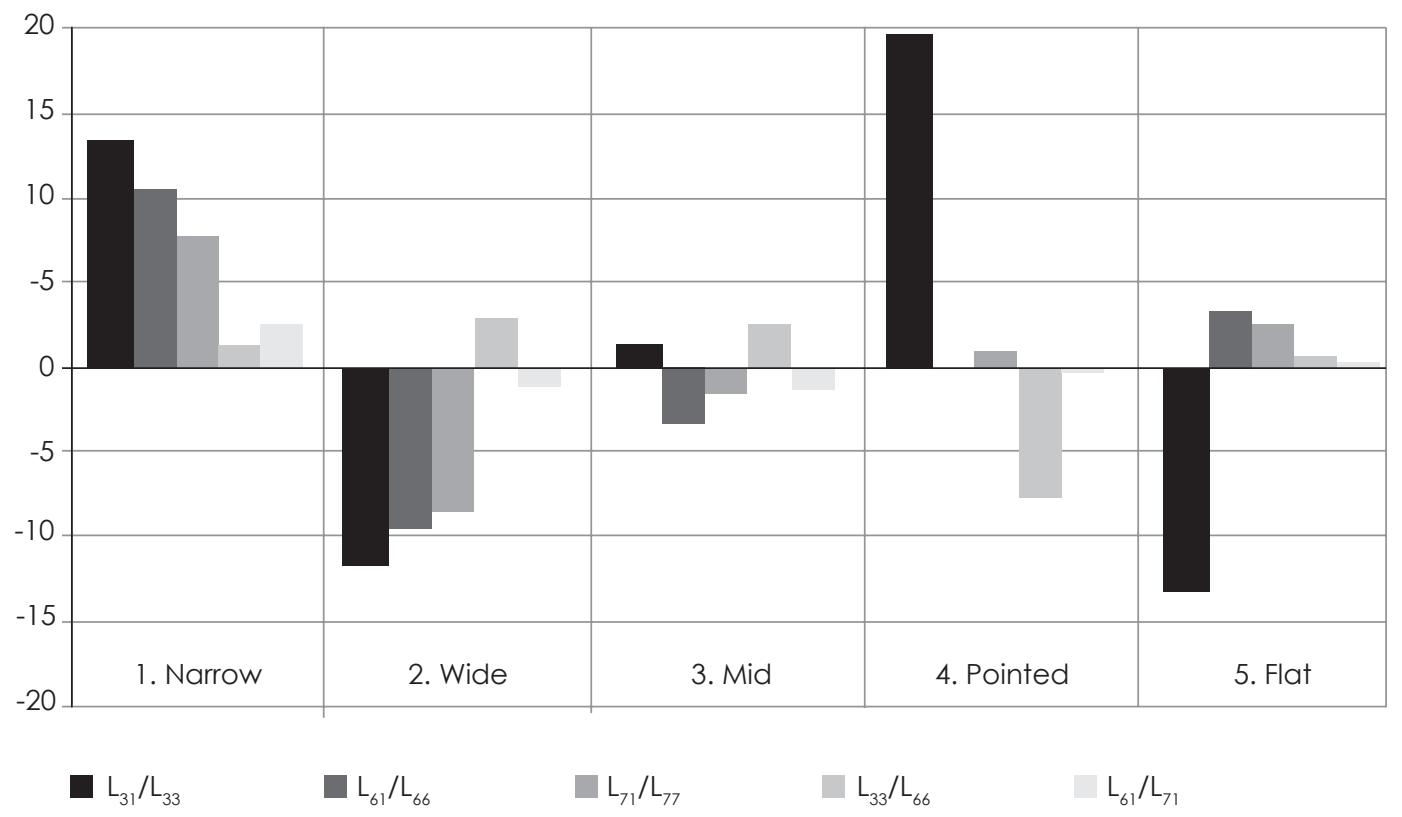

According to the present study; $26 \%$ of the Nepalese adults possess flat dental arch form, $24 \%$ wide arch form, $19 \%$ pointed arch form, $18 \%$ narrow arch form and $13 \%$ mid arch form (Table 4). 
Table 4: Mean value of the independent ratios

\begin{tabular}{|c|c|c|c|c|c|c|}
\hline \multirow{2}{*}{ Arch Form Type } & \multicolumn{2}{|c|}{ Female } & \multicolumn{2}{|c|}{ Male } & \multicolumn{2}{|c|}{ Total } \\
\hline & $\mathbf{N}$ & $\%$ & $\mathbf{N}$ & $\%$ & $\mathbf{N}$ & $\%$ \\
\hline Form 1: Narrow & 13 & 26 & 5 & 10 & 18 & 18 \\
\hline Form 1: Wide & 6 & 12 & 18 & 36 & 24 & 24 \\
\hline Form 1: Mid & 4 & 8 & 9 & 18 & 13 & 13 \\
\hline Form 1: Pointed & 12 & 24 & 7 & 14 & 19 & 19 \\
\hline Form 1: Flat & 15 & 30 & 11 & 22 & 26 & 26 \\
\hline Total & \multicolumn{2}{|c|}{50} & \multicolumn{2}{|c|}{50} & \multicolumn{2}{|c|}{100} \\
\hline
\end{tabular}

\section{DISCUSSION}

In the present study, sagittal and transverse measurements of the mandibular dental arch were taken from the reproducible reference points. Raberin found strong correlation between these reference points. According to Raberin, these points constitute the landmarks that define breaking points of the mandibular arch that limit sectors on which different muscle groups act. The analysis method also follows the segment concept of Robnett ${ }^{26}$ which comprise of anterior segment, premolar-molar segment and a molar line. Besides, the mandibular dental arch is considered very important for diagnosis and treatment planning in orthodontics. Its consistency in form and dimension is a factor of stability of treatment results. ${ }^{27}$

The arch forms depicted by this method basically show two trends: relatively stretched arches illustrated by Form 1 (narrow), and Form 4 (pointed); and relatively stocky arches illustrated by the Forms 2 (wide), 3 (mid), and 5 (flat) (Figure 2).

The polynomial equation used in this study is an equation of the sixth degree, of minimal complexity, enabling to trace curves through the reference points. The polynomial functions of the fourth and the sixth degrees are the most described mathematical methods of arch form analysis. ${ }^{28,29}$ The method associates the $X$-axis with the posterior width of the arch and the $Y$-axis with the axis of arch symmetry, which is also the case in most analogous studies. ${ }^{30,31,32}$

The primary finding of this study is that the Nepalese adults have the highest prevalence of flat dental arches comprising of $26 \%$ of the total samples studied.
Flat arch is more predominant in female $(30 \%)$ than in male (22\%). Thus, in highest proportion of the Nepalese samples the anterior curvature of the mandibular dental arch is less marked. Anterior curve is characterized by the independent ratio $L_{31} / L_{33}$. According to Interlandi, 22 this part of the dental arch depends on incisive-canine arch length. He considered the anterior segment of the dental arch as a perfect curve with a varying length.

Wide dental arch is the second most predominant arch form type, which comprise of $24 \%$ of the total sample studied. Nepalese male samples possess fairly high percentage of wide dental arch (36\%) while females possess only $12 \%$. This is also evident from the fact that all transverse dimensions of males were significantly greater than those of the females. Other study on dental arch width measurement on Nepalese adults also showed a similar trend that mean arch widths in Nepalese males were significantly greater than that of the females. ${ }^{33}$

The distribution of total subjects according to five dental arch form types varied between $13 \%$ to $26 \%$. The study shows that the distribution of arch forms between the sexes is not similar. Male samples show the predominance of relatively stocky dental arches illustrated by $36 \%$ wide and $22 \%$ flat arches while female samples possess relatively stretched arches illustrated by $26 \%$ narrow and $24 \%$ pointed arches. In contrast, males possess only $10 \%$ of narrow and $14 \%$ of pointed arches; and females possess only $12 \%$ wide and $8 \%$ mid arch forms.

When comparing the results of the present study with the results of Raberin ${ }^{24}$ on French adults; the study shows that the distribution of arch form types is different 
Table 5: Comparison of arch form distribution among Nepalese and other racial groups (in \%)

\begin{tabular}{|l|c|c|c|c|}
\hline Arch Form Type & Caucasian (Raberin) & Indian (Irey) & Chinese (Irey) & Nepalese (Shrestha) \\
\hline Form 1: Narrow & 23.7 & 26.6 & 13.3 & 18 \\
\hline Form 1: Wide & 19.7 & 36.6 & 46.7 & 24 \\
\hline Form 1: Mid & 18.7 & 16.6 & 30.0 & 13 \\
\hline Form 1: Pointed & 19.4 & 13.3 & 3.3 & 19 \\
\hline Form 1: Flat & 18.3 & 6.6 & 6.6 & 26 \\
\hline \multicolumn{1}{|c|}{ N } & 278 & 30 & 30 & 100 \\
\hline
\end{tabular}

in two population groups. The narrow arch form is the most predominant type in Caucasians (23.7\%) while it stands as the fourth predominant group among the Nepalese (18\%). On the other hand, flat arch is the least predominant type in Caucasians (18.3\%) while it stands as the most predominant group in Nepalese samples (26\%). These facts could be attributed to racial variations in dental arch forms and dimensions among the population groups.

When comparing the distribution of arch forms in Nepalese adults with those of the Indian and Chinese population groups; ${ }^{34}$ the present study shows that the arch forms are predominated by the flat type in Nepalese samples while wide types are predominant in Indian and Chinese samples (Table 5).

Many pioneer researchers tried to determine a single, ideal arch form that can be used in clinical practice. However, the present study confirms that the dental arch forms do not present a single or universal form, but there are at least five different clinical types seen in untreated adults with symmetrical arch and normal occlusion.

\section{CONCLUSION}

The arch form analysis of the Nepalese adults was based on the mathematical method developed by Raberin et al which classified the mandibular dental arch into five morphological types. The distribution of arch form types were: $26 \%$ flat arch, $24 \%$ wide arch, $19 \%$ pointed arch, $18 \%$ narrow arch and $13 \%$ mid arch form. The distribution of arch form types in Nepalese females and males were not similar. The male samples possessed the predominance of wide arch (36\%) while females possessed the predominance of flat arch $(30 \%)$. Similarly, a considerable variation was noted in the distribution of dental arch forms when the data were compared to Caucasian standard. Further study on the subject is recommended with larger sample size within the ethnic groups among the Nepalese population. 


\section{REFERENCES}

1. Hunter J. The natural history of the human teeth. American library of dental science. Am J Dent Sc 1839; 1: 1-75.

2. Muhlreiter E. Anatomic des menschlichen Gebisses, mit besonderer, Rucksicht auf die Zahnevsatzkunde, Leipzig, 1870.

3. Broombell IN. Anatomy and histology of the mouth and teeth. 2nd ed., Philadelphia, P. Blakiston's Son \& Co., p. $99,1902$.

4. Angle EH. Treatment of malocclusion of the teeth. 7th ed., S S White Dental Mfg Co., 1907.

5. Lasher MH. A consideration of the principles of mechanical arches as applied to the dental arch. Angle Orthod 1934 ; 4: $248-68$.

6. Hawley CA. Determination of the normal arch and its application to orthodontics. Dent Cosmos 1905; 47:541-552.

7. Bonwill WGA. Geometric and mechanical laws of articulation. Trans Odont Soc Penna 1885; $119-133$.

8. Sicher H. Oral anatomy 1952; 2nd ed. C V Mosby Co. St Louis; p. 262-3.

9. MacConaill MA, Scher EA. The ideal form of the human dental arcade, with some prosthetic application. Dent Rec 1949; 69:285302.

10. Scott JH. The shape of the dental arches. J Dent Res 1957; 36:6:996-1003.

11. Burdi AR, Lillie JH: A catenary analysis of the maxillary dental arch during human embryogenesis. Anat Rec 1966; $154: 13-20$.

12. Biggerstaff RH. Three variations in dental arch form estimated by a quadratic equation. J Dent Res 1972; 51:1509.

13. Sampson PD. Dental arch shape: A statistical analysis using conic sections. Am J Orthod 1981; 79(5):535-48.

14. Brader AC. Dental arch form related with intraoral forces: PR=C. Am J Orthod 1972; 61(6):541-61.

15. Lu KH. An orthogonal analysis of the form, symmetry, and asymmetry of the dental arch. Arch Oral Biol 1966; $11: 1057-69$.

16. Ferrario VF, Sforza C, Miani A Jr, Tartaglia G. Mathematical definition of the shape of dental arches in human permanent healthy dentitions. Eur J Orthod 1994; 16:287-294.

17. Ferrario VF, Sforza C, Miani A Jr, Tartaglia G. Human dental arch shape evaluated by Euclidean-distance matrix analysis. Am J Phys Anthraopol 1993; 90(4):287-294.

18. Kasai K, Kanazawa E, Aboshi H, Richards L, Matsuno M. Dental arch form in three Pacific populations: A comparison with Japanese and Australian aboriginal samples. J Nihon Univ Sch Dent 1997; 39(4):196-201.

19. Valenzuela AP, Pardo MA, Yezioro S. Description of dental arch form using the Fourier series. Int J Adult Orthod Orthognath Surg $2002 ; 17(1): 59-65$.

20. Begole EA, Lyew RC. A new method for analyzing change in dental arch form. Am J Orthod Dentofacial Orthop 1998; $113(4)$ :394401.

21. Data Bits Newsletter No. 2,3,5. Rocky Mountain Data Systems, Sherman Oaks, CA, 1976.

22. Interlandi S. New method for establishing arch form. J Clin Orthod 1978; 12:843-5.

23. Mclaughlin R, Bennett JC. Arch form considerations for stability and esthetics. Rev Esp Orthod 1999; $29(2): 46-63$.

24. Raberin M, Laumon B, Martin J, Brunner F. Dimension and form of dental arches in subjects with normal occlusion. Am J Orthod dentofacial orthop 1993; 104(1):67-72.

25. Aitchison J. Some racial contrasts in teeth and dental arches. Dent Mag and Oral topics 1965; 82:201-5.

26. Robnett JH. Segment concept in arch pattern design. Am J Orthod 1980; 77(4):355-367.

27. Little RM, Wallen TR, Riedel RA. Stability and relapse of mandibular anterior segment. Am J Orthod 1981; 80:349-65.

28. Sanin C, Savara BS, Thomas DR, Clarkson QD. Arc length of the dental arch estimated by multiple regression. J Dent Res 1970 ; $49: 4: 885$.

29. BeGole EA. Application of cubic spline function in the description of dental arch form. J Dent Res 1980; 59:1549-56.

30. Pepe SH. Polynomial and catenary curve fits to human dental arches. J Dent Res 1975; 54(6):1124-32.

31. Herren P, Schmoker R, Jordi T. Arch shape and space balance determined by arcogramme technique. Trans Eur Orthod Soc $1973 ; 61-72$

32. Sampson PD. Dental arch shape: A statistical analysis using conic sections. Am J Orthod 1981; 79(5):535-548.

33. Shrestha RM, Bhattarai P. Dental arch width analysis of Nepalese adults using Lavelle's method. J Nep Dent Asso 2008 ; 9 (1):7-14.

34. Irey M, Valiathan A, Krishnaprasad K. Comparison and classification of dental arch forms of Indian and Chinese subjects with normal occlusions. Ind J dent Res 1998; 9(2):47-57. 